University of Wollongong

Research Online

Faculty of Social Sciences - Papers (Archive) Faculty of Arts, Social Sciences \& Humanities

2000

Severe maternal psychopathology and infant-mother attachment

A E. Hipwell

University of London

Frits Goossens

Vrije Universiteit Amsterdam

Edward Melhuish

University of Wollongong, melhuish@uow.edu.au

R Kumar

University of London

Follow this and additional works at: https://ro.uow.edu.au/sspapers

Part of the Education Commons, and the Social and Behavioral Sciences Commons

Research Online is the open access institutional repository for the University of Wollongong. For further information contact the UOW Library: research-pubs@uow.edu.au 


\title{
Severe maternal psychopathology and infant-mother attachment
}

\begin{abstract}
Eighty-two mother-infant dyads, comprising women with psychiatric disorder and individually matched controls, were followed up over the children's 1 st year of life. The mothers with mental illness consisted of two subgroups: first, 25 severely mentally ill mothers who had been admitted to a psychiatric unit with their infants; and second, 16 mothers from a community sample meeting research diagnostic criteria for unipolar, nonpsychotic depression. With the exception of six dyads in the in-patient group, observations were made of the mother-infant interaction and the quality of the infant-mother attachment relationship at 12 months. The nature and course of the mothers' illness was also documented. Although few residual symptoms of maternal mental illness were detected at 1 year postpartum, interactional disturbances were evident among the case group dyads. A strong association was revealed between infant-mother attachment quality and maternal diagnosis: a manic episode of illness in the postpartum period was related to security in the attachment relationship, and psychotic or nonpsychotic depression was related to insecurity. Concurrent patterns of mother-infant interaction provided support for this finding.
\end{abstract}

\section{Keywords}

mother, attachment, infant, maternal, psychopathology, severe

\section{Disciplines}

Education | Social and Behavioral Sciences

\section{Publication Details}

Hipwell, A. E., Goossens, F. A., Melhuish, E. C. \& Kumar, R. (2000). Severe maternal psychopathology and infant-mother attachment. Development and Psychopathology, 12 (2), 157-175. 


\title{
Severe maternal psychopathology and infant-mother attachment
}

\author{
A. E. HIPWELL,${ }^{a}$ F. A. GOOSSENS,${ }^{b}$ E. C. MELHUISH ${ }^{c}$ AND R. $\operatorname{KUMAR}^{a}$ \\ ${ }^{a}$ University of London; ${ }^{b}$ Free University, Amsterdam; and ${ }^{c}$ University of Wales
}

\begin{abstract}
Eighty-two mother-infant dyads, comprising women with psychiatric disorder and individually matched controls, were followed up over the children's 1st year of life. The mothers with mental illness consisted of two subgroups: first, 25 severely mentally ill mothers who had been admitted to a psychiatric unit with their infants; and second, 16 mothers from a community sample meeting research diagnostic criteria for unipolar, nonpsychotic depression. With the exception of six dyads in the in-patient group, observations were made of the mother-infant interaction and the quality of the infant-mother attachment relationship at 12 months. The nature and course of the mothers' illness was also documented. Although few residual symptoms of maternal mental illness were detected at 1 year postpartum, interactional disturbances were evident among the case group dyads. A strong association was revealed between infant-mother attachment quality and maternal diagnosis: a manic episode of illness in the postpartum period was related to security in the attachment relationship, and psychotic or nonpsychotic depression was related to insecurity. Concurrent patterns of mother-infant interaction provided support for this finding.
\end{abstract}

The possible contribution of the experience of parental mental illness to childhood disturbance and the relative importance of associated factors is not well understood. The nature and duration of the parent's illness, the type of treatment given, the child's age at the time of exposure to the disorder, the extent of family discord, separations, or social adversity, and whether or not the affected parent is the child's primary caregiver are all likely to have some influence. Much research has focused on the nature of potential disturbances in the

This research was supported by a grant from the Bethlem Royal and Maudsley Hospitals Special Health Authority. We gratefully acknowledge the work carried out by Charlie Stanley in coding for D attachment status, and the independent ratings made by Oonagh Costello and Christine Platz. We are indebted to Dieter Wolke for his generous training in the use of the Play Observation Scheme and Emotion Rating, and to Lynne Murray for her valuable comments on an earlier version of this paper.

Address correspondence and reprint requests to: Dr. A. E. Hipwell, Section of Perinatal Psychiatry, Department of Psychiatry, Institute of Psychiatry, University of London, DeCrespigny Park, Denmark Hill, London SE5 $8 \mathrm{AF}, \mathrm{UK}$. parents' caregiving ability and has revealed many ways in which maternal psychopathology may affect interactions with the offspring ranging from extreme withdrawal, disengagement, inactivity, and understimulation to intrusiveness, inconsistency, hostility, and overstimulation (Cummings \& Cicchetti, 1990; Field, Healy, Goldstein, \& Guthertz, 1990; Goodman \& Brumley, 1990; Lyons-Ruth, Zoll, Connell, \& Grunebaum, 1986; Pound, Cox, Puckering, \& Mills, 1985; Teti \& Nakagawa, 1990).

Several studies have demonstrated the sophistication with which the healthy infant is able to elicit and engage in social interaction in the immediate postpartum months. In addition they have highlighted the central role that dyadic attunement with an emotionally available and sensitive primary caregiver plays in the development of infant affect regulation and cognitive skills (e.g., Cohn \& Tronick, 1989; see reviews by Murray, 1988; Stern, 1985). There may be times when the mentally ill mother has difficulty in responding sensitively to her infant; indeed, the quality of 
mother-infant interaction in the context of nonpsychotic postnatal depression has been described as being less positive, less spontaneous or mutually contingent, and containing less "child centered" speech than in healthy controls (Cohn, Campbell, Matias, \& Hopkins, 1990; Field et al., 1990; Field, 1992; Fleming, Ruble, Flett, \& Shaul, 1988; Murray, 1992; Murray, Fiori-Cowley, Hooper, \& Cooper, 1996; Murray, Kempton, Woolgar, \& Hooper, 1993). In several of these studies the infants showed signs of fussiness or flat affect or inactivity and were less responsive to the environment.

Further reason for concern about disturbances in mother-infant interaction in the postpartum period is provided by evidence to suggest that improvements in the quality of the interaction between mother and infant after the first 6 months postpartum may not be associated with improved outcome for the child's cognitive and emotional development either in healthy samples (e.g., Grossmann, Grossmann, Spangler, Suess, \& Unzner, 1985; van Ijzendoorn, Juffer, \& Duyvesteyn, $1995)$ or in samples where the mother has had nonpsychotic postnatal depression (Cogill, Caplan, Alexandra, Robson, \& Kumar, 1986; Field, 1992; Hay \& Kumar, 1995; LyonsRuth et al., 1986; Murray, 1992; Sharp, Hay, Pawlby, Schmücker, \& Kumar, 1995; Stein, Gath, Bucher, Bond, Day, \& Cooper, 1991). The work of Field, Healy, Goldstein, Perry, Schanberg, Zimmerman, and Kuhn (1988) has demonstrated the codirectionality of effects of depression among mothers and their offspring which may serve to maintain disturbances in interactional dialogues despite remission of the mother's symptoms.

The strategy used by children to relate to their primary attachment figure in the first 12-18 months, which in part reflects the nature and history of early mother-infant interactions (e.g., Ainsworth, Blehar, Waters, \& Wall, 1978; Bates, Maslin, \& Frankel, 1985; Frankel \& Bates, 1990; Goldsmith \& Alansky, 1987; Main, 1983), has also been shown to be an important predictor of subsequent psychological development and of the establishment of relationships outside the family (e.g., Bowlby, 1982; Bretherton, 1985; Cic- chetti, Ganiban, \& Barnett, 1991; Cicchetti \& Toth, 1998; Cummings \& Cicchetti, 1990; Lyons-Ruth, Easterbrooks, \& Cibelli, 1997; Renken, Egeland, Marvinney, Mangelsdorf, \& Sroufe, 1989; van Ijzendoorn, van der Verr, \& van der Vliet-Visser, 1987). This strategy has been shown to remain constant in both the short term (e.g., 6 months; Connell, 1977; Main \& Weston, 1982; Waters, 1978) and the long term (e.g., up to 5 years; Main, Kaplan, \& Cassidy, 1985) under "stable life conditions." Although families with a depressed mother are likely to experience less than stable life conditions, there is nevertheless evidence that exposure to maternal postnatal (nonpsychotic) depression makes a significant contribution to insecurity in the attachment relationship (Cicchetti, Rogosch, \& Toth, 1998; Field, 1992; Lyons-Ruth et al., 1986; Murray, 1992). Such findings have major clinical implications for primary intervention and prevention of childhood psychopathology.

In comparison with the accruing body of research into the impact of maternal nonpsychotic depression on the developing infant, there has been relatively little systematic research of infants whose mothers have been affected by more severe psychiatric disorders such as schizoaffective and bipolar illnesses in the postpartum period. One might expect to find substantial adverse effects on the child given the degree of impairment in the mother's mental state and in her ability to look after her infant (Appleby \& Dickens, 1993; DeMulder \& Radke-Yarrow, 1991; Hipwell \& Kumar, 1996; Kumar, 1992; Kumar \& Hipwell, 1994, 1996; Kumar, Marks, Platz, \& Yoshida, 1995; Margison, 1982, 1990; Melhuish, Gambles, \& Kumar, 1988; Radke-Yarrow, Cummings, Kuczynski, \& Chapman, 1985; Radke-Yarrow, McCann, DeMulder, Belmont, Martinez, \& Richardson, 1995).

During an episode of illness, mothers diagnosed with bipolar disorder may experience rapid mood swings, periods of severe depression, or periods of mania with behaviors such as overactivity, accelerated speech, distractibility, irritability, euphoria, and grandiosity. Infants of mothers with a schizoaffective disorder may also be exposed to extreme disturb- 
ances in caregiving and to bizarre, unpredictable behavior resulting from psychiatric symptoms such as hallucinations and delusional thoughts, which may be specifically focused on the infant (Margison, 1990; Thiels \& Kumar, 1987). The degree of impairment in caregiving may be related to the nature of the mother's mental illness (Hipwell \& Kumar, 1996), with mothers diagnosed as schizophrenic being rated by nursing staff as the most impaired in their care of their infant, followed by mothers with a manic, a bipolar, and finally a depressive disorder. Several studies have shown that compared to control dyads, the interactions between infants and mothers who have a history of psychosis (but who are not necessarily currently mentally ill) appear to be more frequently tense and disorganized, with less shared affect and mutual enjoyment and fewer reciprocal behaviors. Case group mothers have been described as more insensitive to and uncertain about the infant's needs (Davenport, Zahn-Waxler, Adland, \& Mayfield, 1984; McNeil, Näslund, Persson-Blennow, \& Kaij, 1985; Persson-Blennow, Näslund, McNeil, \& Kaij, 1986).

To date, confident evaluation of the outcome for the offspring of severely mentally ill mothers has not been possible because previous studies have often failed to detail the nature, timing, and duration of psychiatric treatment and management, such as hospital admissions, and the resulting effects of separations and disruption of the family. This may underlie discrepant findings; for example, some researchers have reported an increased risk of insecure infant-mother attachment in the context of severe maternal mental illness (e.g., Cytryn, McKnew, Zahn-Waxler, RadkeYarrow, Gaensbauer, Harmon, \& Lamour, 1984; DeMulder \& Radke-Yarrow, 1991; Gaensbauer, Harmon, Cytryn, \& McKnew, 1984; Radke-Yarrow et al., 1985; van Ijzendoorn, Goldberg, Kroonenberg, \& Frenkel, 1992), while others have not (McNeil, Persson-Blennow, Binett, Harty, \& Karyd, 1988; Näslund, Persson-Blennow, McNeil, Kaij, \& Malmquist-Larsson, 1984; Persson-Blennow, Binett, \& McNeil, 1988; Sameroff, Seifer, \& Zax, 1982). In addition, inconsistent findings are likely to be due to small sample sizes, dif- ferences in the social circumstances of the families and in the ages of the offspring studied, differences in the criteria used to assess adult psychiatric diagnoses, changes in the attachment classification system itself over the past decade, as well as other variations in the administration and scoring of research measures (Cicchetti et al., 1991; Cicchetti, Toth, \& Lynch, 1995; D’Angelo, 1986; Melhuish et al., 1988).

Maternal psychoses which arise in the postpartum period often remit completely within the first few months after delivery and so provide a unique context in which to examine the effects of severe but relatively temporary perturbation of mother-infant interaction. The current study was carried out to examine the quality of the interactions between mother and infant and the nature of infant-mother attachment at 12 months in a group of women who had experienced an episode of severe mental illness and who had been jointly hospitalized with their infants in the postpartum period.

From a clinical standpoint there is an urgent need to examine the outcome for the child as a function of the mother's treatment and management among this high-risk group. The British practice of jointly admitting mentally ill mothers to hospital with their infants is based upon the intuitive assumption that a good affective relationship between mother and child will be facilitated and any disruption due to the mother's disorder will be attenuated. It is possible, however, that there may be adverse effects in the infant, arising not only from exposure to severely disturbed maternal behavior but also from various aspects of institutionalization, such as the experience of multiple substitute caregivers when the mother is too disturbed to cope or care safely for her baby (Kumar, 1992). In the present study, the nature and course of the mother's illness and her treatment and management in the postpartum period were analyzed in relation to the infant's behavior at 12 months.

Three questions were addressed: (a) What is the impact of postpartum maternal mental illness on the infant-mother relationship at 12 months? (b) What is the impact of the affective nature of severe maternal mental disorder 
occurring in the postpartum period? (c) Does the impact of severe postnatal depression requiring hospitalization differ from the effects of less severe depression without hospitalization?

\section{Method}

\section{Sample characteristics}

The sample comprised two case groups in which the mothers had experienced a postnatal illness and one matched control group. In the first case group (in-patients), the mothers had been diagnosed as suffering from a severe psychiatric disorder and had been jointly admitted with their infants to a specialized psychiatric unit in the months following childbirth $(n=25)$. In the second case group, a community-based group, the mothers had experienced a nonpsychotic unipolar depression (meeting RDC criteria for definite major or minor depression) that was less severe than in the former group and these mothers and infants had continued to live at home throughout the illness $(n=16)$. The control group consisted of individually matched, psychiatrically healthy mothers and their infants $(n=$ 41). Pairwise matching was employed to reduce the covariance of factors such as social class and marital status with mental illness within the relatively small and heterogeneous case groups (e.g., Murray et al., 1996; Sameroff et al., 1982).

\section{In-patient (IP) group}

Mothers were recruited from a psychiatric mother and baby unit (MBU) which offers treatment to patients with severe puerperal mental illness from a wide area of southeast England. Out of 48 women jointly admitted with their infants to the MBU during a 20month period, 25 dyads met the following criteria and were recruited into the IP group: (a) the infant was more than 36 weeks gestation and $2500 \mathrm{~g}$ at birth, (b) mother and infant were admitted to the MBU prior to 10 weeks postpartum and for a period of at least 2 weeks, (c) mother and infant were discharged
Table 1. Diagnostic status of the in-patient (IP) and the community depressed (CD) group mothers

\begin{tabular}{|c|c|}
\hline RDC Diagnoses & $n$ \\
\hline \multicolumn{2}{|l|}{ IP group } \\
\hline Nonpsychotic depression & \\
\hline $\begin{array}{l}\text { Major depressive disorder } \\
\text { (nonpsychotic) }\end{array}$ & 5 \\
\hline $\begin{array}{l}\text { Major depressive disorder and } \\
\text { alcoholism }\end{array}$ & 1 \\
\hline $\begin{array}{l}\text { Major depressive disorder and panic } \\
\text { disorder }\end{array}$ & 1 \\
\hline \multicolumn{2}{|l|}{ Psychotic depression } \\
\hline $\begin{array}{l}\text { Schizoaffective disorder-depressed } \\
\text { type }\end{array}$ & 2 \\
\hline Major depressive disorder (psychotic) & 1 \\
\hline $\begin{array}{l}\text { Unspecified functional psychosis with } \\
\text { depressive features }\end{array}$ & 2 \\
\hline \multicolumn{2}{|l|}{ Manic disorder } \\
\hline Manic disorder & 5 \\
\hline Schizoaffective disorder-manic type & 3 \\
\hline \multicolumn{2}{|l|}{ Bipolar disorder } \\
\hline Bipolar (I) illness & 2 \\
\hline $\begin{array}{l}\text { Bipolar (I) illness and major depressive } \\
\text { disorder }\end{array}$ & 1 \\
\hline $\begin{array}{l}\text { Schizoaffective disorder-manic type } \\
\text { and bipolar (II) illness }\end{array}$ & 2 \\
\hline \multicolumn{2}{|l|}{ CD group } \\
\hline Major depressive disorder & 8 \\
\hline Minor depressive disorder & 8 \\
\hline
\end{tabular}

home together, (d) the mother was not experiencing a chronic schizophrenic illness.

Psychiatric diagnoses according to the Research Diagnostic Criteria (RDC; Spitzer, Endicott, \& Robins, 1978) were made independently by two psychiatrists following the admission and are shown in Table 1. Diagnostic concordance was achieved for 23 (92\%) of the mothers; the diagnoses of the remaining 2 cases was agreed by consensus.

All of the five women in the current sample who were given a diagnosis of bipolar disorder experienced at least one episode of mania in addition to depression in the postpartum period under study. An episode of major depressive disorder was classified as psychotic if the woman had experienced depressive delusions, such as delusions of guilt, sin, poverty, nihilism, or self-deprecation, or hallucinations with similar content.

The IP sample was broadly representative 
of 100 consecutive admissions to the MBU described by Kumar et al. (1995), although there was a slight bias towards early onset cases. Cases with chronic schizophrenia were excluded from the study because (a) there were too few such subjects admitted in the time available to permit meaningful analyses; and (b) the study was restricted to those women with predominant mood disorder, in whom the likelihood of substantial recovery in the short to medium term was high. In order to examine the impact of the affective nature of the mothers' illness on the child, the IP groups comprising "nonpsychotic and psychotic depression" were combined, as were "manic and bipolar disorder." The onset and nature of the symptoms that the mothers presented was variable, but in cases where psychotic ideation arose, the focus was often the infant. During admission, practical competence in infant care and the nature of the emotional bond with the child also varied and was generally associated with the degree of disturbance in mental state, although some mothers expressed concern about their feelings towards the infant after symptoms had remitted.

\section{“Community depressed" (CD) group}

The group of CD mothers (see Table 1) was recruited from a sample of 182 women who took part in an antenatal screening study for postnatal depression carried out at the local maternity hospital. Twenty-six of the 128 women who also responded at 6 weeks postpartum scored more than 12 on the Edinburgh Postnatal Depression Scale (EPDS; Cox, Holden, \& Sagovsky, 1987). Of these 26 mothers, 16 fulfilled diagnostic criteria for definite minor or major depression (Schedule for Affective Disorders and Schizophrenia [SADS]; Endicott \& Spitzer, 1978) and were available for follow-up. Complete agreement on psychiatric diagnosis was reached independently between the trained recruiting psychologist and a psychiatrist.

\section{Control group}

Of 51 mothers approached, 41 women were recruited with their infants from the postdeliv- ery wards at two local hospitals to make up the control group. The dyads were matched with individual mothers and infants from the two case groups on the following criteria: maternal age (within 1 year for mothers less than 20 years old, and within 2 years for mothers more than 20), parity (for two multiparae, close, rather than exact, matches were achieved), ethnic group, sex of the baby, presence or otherwise of a stable relationship, and occupational status (of the partner unless the mother was single) using the Registrar General's Classification (1980). None of these women experienced an episode of mental illness during the period of study, and none had a history of psychiatric disorder or had ever received professional help for emotional problems.

The demographic characteristics of the two case groups with their paired controls are shown in Table 2.

\section{Procedure}

The mother-infant pairs $(n=82)$ were followed prospectively until 12 months postpartum. Ratings of the quality of mother-infant interaction in the first months after delivery were made using the Bethlem Mother-Infant Interaction Scale (Kumar \& Hipwell, 1996) and are reported elsewhere (Hipwell \& Kumar, 1996).

At 12 months the mothers were asked whether they would be willing to participate in a videotaped laboratory-based play session with their infants. All but six of the women consented to take part $(n=76)$; those who refused this part of the study were all from the IP group. Three of the 6 mothers had been given diagnoses of manic/bipolar disorder, and 3 of unipolar depression (one nonpsychotic, two psychotic depressions). Of the refusing women, 3 were continuing to report some symptoms of depression at 12 months, and 1 mother was currently manic during the interview. This woman was living in closely supervised accommodation in the community and the others were receiving out-patient psychiatric care.

In contrast, the 19 mothers in the IP group who did agree to participate were free from 
Table 2. Demographic characteristics of the in-patient (IP) and community depressed (CD) groups with their paired controls

\begin{tabular}{|c|c|c|c|c|c|c|c|c|c|c|c|c|}
\hline & \multicolumn{3}{|c|}{$\begin{array}{l}\text { IP Group } \\
(n=25)\end{array}$} & \multicolumn{3}{|c|}{$\begin{array}{l}\text { Control Group } \\
\quad(n=25)\end{array}$} & \multicolumn{3}{|c|}{$\begin{array}{l}\text { CD Group } \\
(n=16)\end{array}$} & \multicolumn{3}{|c|}{$\begin{array}{l}\text { Control Group } \\
\quad(n=16)\end{array}$} \\
\hline & $M$ & $S D$ & $\begin{array}{l}\text { Min- } \\
\operatorname{Max}\end{array}$ & $M$ & $S D$ & $\begin{array}{l}\text { Min- } \\
\operatorname{Max}\end{array}$ & $M$ & $S D$ & $\begin{array}{l}\text { Min- } \\
\text { Max }\end{array}$ & $M$ & $S D$ & $\begin{array}{l}\text { Min- } \\
\text { Max }\end{array}$ \\
\hline Age of mother (years) & 29.5 & 5.8 & $19-41$ & 29.8 & 4.6 & $18-39$ & 28.9 & 6.5 & $19-39$ & 28.8 & 6.9 & $20-41$ \\
\hline \multirow{2}{*}{\multicolumn{13}{|c|}{$\begin{array}{l}\text { Infant age at onset } \\
\quad \text { (weeks) }\end{array}$}} \\
\hline & 1.7 & 1.8 & $0-7$ & - & - & - & 1.7 & 2.0 & $0-6$ & - & - & - \\
\hline Infant age on admission & & & & & & & & & & & & \\
\hline $\begin{array}{l}\text { (weeks) } \\
\text { (wength of admission }\end{array}$ & 4.1 & 3.5 & $1-10$ & - & - & - & - & - & - & - & - & - \\
\hline $\begin{array}{l}\text { Length of admission } \\
\text { (weeks) }\end{array}$ & 11.5 & 5.9 & $3-23$ & - & - & - & - & - & - & - & - & - \\
\hline \multirow[t]{2}{*}{$\begin{array}{l}\text { Remission of illness } \\
\text { (weeks) }\end{array}$} & 36.5 & 13.9 & $8-50$ & - & - & - & 35.9 & 15.4 & $12-52$ & - & - & - \\
\hline & & $n$ & $\%$ & & $n$ & $\%$ & & $n$ & $\%$ & & $n$ & $\%$ \\
\hline Primiparous & & 16 & 64 & & 16 & 64 & & 9 & 56 & & 9 & 56 \\
\hline Male infant & & 11 & 44 & & 11 & 44 & & 10 & 63 & & 10 & 63 \\
\hline Married/cohabiting & & 20 & 80 & & 20 & 80 & & 14 & 88 & & 14 & 88 \\
\hline \multicolumn{13}{|l|}{ Occupation } \\
\hline Nonmanual & & 15 & 60 & & 19 & 76 & & 10 & 63 & & 15 & 94 \\
\hline Manual & & 10 & 40 & & 9 & 24 & & 6 & 37 & & 1 & 6 \\
\hline
\end{tabular}

psychiatric disorder at the time of the laboratory assessments. During the postpartum period, 9 of these women had been given a diagnosis of nonpsychotic or psychotic depressive disorder and 10 of manic or bipolar disorder. All 16 of the CD depressed group and all of the respective controls for both case groups agreed to take part.

Filming of the quality of mother-infant interaction and attachment relationship was conducted in a studio that allowed high-quality recordings to be made. After an initial "warm-up" period, the mother and infant were given four toys to play with consecutively "in any way they wanted," each for a period of $2.5 \mathrm{~min}$. Two of the toys were age appropriate for the infants and the aim was to provide an opportunity for social interaction and reciprocity in play. The other two were more complex, providing a need for the mother to mediate, and be emotionally available for the child to complete the game correctly, and an opportunity to observe the infant's motivation, task orientation, and compliance with the mother's suggestions and expectations.

Following a short interval, the standard
Strange Situation procedure (Ainsworth et al., 1978) was carried out in order to assess infant-mother attachment security. The mother and infant were reintroduced to the playroom, which was laid out with a selection of previously unseen toys. An experimenter who had had no contact with the dyad took the role of the stranger. None of the children had experienced a significant separation from the mother within 2 weeks of the laboratory session.

\section{Measures}

\section{Maternal psychopathology}

The nature and course of the mother's mental state was documented at 2 and at 12 months using the SADS interview for all the groups. For the IP group, the information gathered from the 2-month SADS was combined with all other available sources of information about the mother's history and illness to derive an RDC diagnosis agreed by two psychiatrists (Kumar et al., 1995). The retrospective reports of symptoms experienced in the post- 
partum period collected at the 12-month SADS interview were consistent with the 2month assessments. The current mental state of the mothers in the CD and control groups was confirmed by an independent psychiatrist. Type and dosage of medication that was being prescribed and taken, and contact with mental health workers were noted.

\section{Mother-infant interaction and attachment security}

Dimensions of mother-infant interaction were coded using the Play Observation Scheme and Emotion Rating (POSER; Wolke, 1986), which comprised empirically and conceptually derived global rating scales from previous work of the interactions of disturbed and well mothers and their infants. The scales provided a means by which to examine affective and behavioral characteristics of the mother-infant interaction, such as maternal facilitation and regulation of the child's behavior, the mother's sensitivity and mood, the appropriateness of her play, and her expectations about the child's ability and conformity to control. Infant behaviors (such as attention to and persistence at a task, expressions of affect, quality of communication, and social referencing) and joint behaviors (such as the degree of reciprocity, shared attention, tension, and conflict) were also rated.

Nine maternal, 10 infant, and 3 joint mother-infant behaviors were rated using 5and 9-point scales of the POSER. Sixty-two $(89 \%)$ of the videotaped interactions were rated by a trained psychologist who was unaware of all other information about the mothers and infants. Interrater reliability with a second trained rater was calculated for 19 $(27 \%)$ of these play sessions and was found to vary between 0.69 and 0.97 (intraclass coefficient; Bartko, 1966, 1976) using individual scores on the POSER scales. The remaining eight $(11 \%)$ videotapes were rated by consensus in the training sessions and other coding queries were resolved in these meetings.

The infants' behavior during the Strange Situation was coded by two raters who had both achieved reliability (i.e., more than $80 \%$ agreement) with Alan Sroufe in Minnesota and who were also unaware of all other information including maternal group and POSER ratings. One rater coded for Insecure-avoidant (A), Secure (B), and Insecure-resistant/ambivalent (C) type behaviors (Ainsworth et al., 1978), and the second rater coded independently for Disorganized/disoriented (D) type behaviors (Main \& Solomon, 1990).

\section{Data analysis}

In order to examine the impact on the child of severe postnatal mental illness and joint hospitalization on the quality of the relationship at 1 year, comparisons were made between the IP mother-infant pairs and the matched-pair healthy control group dyads ( $n$ $=19$ ). Similar comparisons were made between the less severely ill community-based dyads, in which the mothers had developed postnatal depression within the first 2 months of delivery, and their corresponding matched controls $(n=16)$.

Secondly, the impact of the nature of the mother's postpartum illness on the quality of the relationship with her infant at 12 months was examined by comparing IP dyads in which the mothers had been either psychotic or nonpsychotically depressed $(n=9)$ with mothers who had experienced a manic or bipolar disorder $(n=10)$. Where differences were revealed between these groups, a comparison was then made with the respective controls to examine whether either case group deviated from the norm, or whether the difference was incorporated within the normal range of behaviors.

The third research question concerning the impact of the severity of maternal depression was examined by making comparisons between the depressed IP group $(n=9)$ and the community-based depressed group $(n=16)$. The independent effects of severe maternal mental illness and hospitalization could not be tested in the current study.

No predictions were made about the direction of effects, and two-tailed tests were used throughout. Because of the small sample sizes, statistical analyses of attachment classifications were necessarily limited. 


\section{Results}

\section{Maternal mental state}

The 19 IP mothers reported that they had made a full recovery from their illness by 36.5 weeks postpartum (range $=8-50$, mode $=42$, $S D=13.9$ ), although the average time of discharge from the MBU was at 15 weeks postpartum $($ range $=6-32$, mode $=11, S D=6.45)$ after an 11-week joint admission (range $=3$ 29 , mode $=10, S D=6.2$ ). The mean time of onset of illness in this group was 2.7 weeks (range $=1-5$, mode $=2, S D=1.5)$. During the course of their admission to the MBU, 12 mothers (3 unipolar, 9 manic/bipolar) had to be "separated" temporarily from their infants due to the severity of the mothers' illness and consequent concerns for the baby's safety. The periods of separation were between 1 and 4 weeks in total. At these times the nurses took on most of the child care and the mothers continued to have limited periods of supervised contact with their infants.

All the case group women were asked to identify the week that they felt their illness was at its "worst." Using information gathered from the SADS at 2 and at 12 months, the IP group women reported this to be at 4 weeks postpartum on average (range $=1-11$, $S D=3.3$ ). During this particular week, the total number of symptoms experienced was 10 (range $=6-16$, mode $=8, S D=3.5) ; 13$ of the 25 women experiencing some psychotic symptoms. Mothers' self-reports and clinical observations indicated that in most cases there was substantial improvement in mental state by 2 months. At 12 months 4 of the IP group mothers complained of some depressive symptoms, but none of these fulfilled diagnostic criteria for major or minor depression. No manic or psychotic symptoms were reported. Three IP mothers were still taking neuroleptics, 3 were taking lithium, and 7 mothers were currently taking antidepressant medication.

The women in the $\mathrm{CD}$ group also reported the onset of their illness as being at 2.7 weeks (range $=1-6$, mode $=1, S D=1.9$ ), and recovery from their illness at 35.9 weeks on average $($ range $=12-52$, mode $=52, S D=15.4)$.
Reports of the "worst week" were at 7 weeks postpartum (range $=2-20$, mode $=4, S D=$ 4.1 , when the mean number of depressive symptoms reported was 8 (range $=5-12$, mode $=7, S D=2.1$ ). No manic or psychotic symptoms were described by any of the women in this group.

At 12 months, 7 of the mothers in the CD group reported some depressive symptoms. Among them, 1 woman described symptoms that met RDC for major depressive disorder and 2 met criteria for minor depression. Four women had been prescribed antidepressant medication by their general practitioners, and 1 had been given sleeping tablets. Three were continuing these medications at 12 months. None of the CD mothers had been separated from their infants as a direct result of their mental illness.

\section{Mother-infant interaction}

Principal components analyses were carried out on the maternal, child, and joint behavior items of the POSER. Five of the 22 items rated were excluded from the analyses: "Maternal physical involvement" and "Rough handling" due to minimal variation in ratings; and "Infant social referencing," "Frequency of infant mouthing," and "Control of the session" because they substantially reduced the internal consistency of the factors produced. Seven components with loadings greater than 0.4 were thus generated from the remaining 17 items (see Table 3). The three maternal behavior components were labeled: (a) "Sensitive involvement," (b) "Affectionate talk," and (c) "Maternal control." Infant behaviors were grouped as (a) "Expressivity," (b) "Task involvement," and (c) "Level of energy." The joint behaviors were represented by one factor called "Quality of interaction," which consisted of the ratings of reciprocity and positive atmosphere of the play interaction.

Because the components were produced from separate analyses, the intercorrelations were examined and are shown in Table 4. Maternal Sensitive involvement and the Quality of interaction were found to be highly correlated with each other $(r=0.76)$ and thus it was decided that Quality of interaction should 
Table 3. Factor loadings from the Principal Components Analyses of the POSER ratings

\begin{tabular}{|c|c|c|c|}
\hline & $\begin{array}{c}\text { Sensitive } \\
\text { Involvement } \\
(37.8 \% \text { of Variance })\end{array}$ & $\begin{array}{l}\text { Affectionate } \\
\text { Talk } \\
(22.7 \%)\end{array}$ & $\begin{array}{c}\text { Maternal } \\
\text { Control } \\
(14.6 \%)\end{array}$ \\
\hline Maternal Behaviors & $r$ & $r$ & $r$ \\
\hline Sensitivity & 0.91 & & \\
\hline Appropriateness of play & 0.81 & & \\
\hline Expressed negative emotion & -0.80 & & \\
\hline Expressed positive emotion & & 0.87 & \\
\hline Frequency of vocalizations & & 0.85 & \\
\hline Verbal control & & & 0.89 \\
\hline \multirow[t]{2}{*}{ Teaching behavior } & & & 0.62 \\
\hline & $\begin{array}{c}\text { Expressivity } \\
(42.7 \%)\end{array}$ & $\begin{array}{c}\text { Task } \\
\text { Involvement } \\
(24.8 \%)\end{array}$ & $\begin{array}{c}\text { Energy } \\
\text { Level } \\
(13.5 \%)\end{array}$ \\
\hline Infant Behaviors & $r$ & $r$ & $r$ \\
\hline Vocalization level & 0.92 & & \\
\hline Frequency of vocalizations & 0.88 & & \\
\hline Emotional tone & 0.65 & & \\
\hline Quality of communication & 0.75 & & \\
\hline Task orientation & & 0.96 & \\
\hline Persistence & & 0.94 & \\
\hline Activity level & & & 0.92 \\
\hline \multirow[t]{2}{*}{ Intensity } & & & 0.76 \\
\hline & $\begin{array}{c}\text { Interaction Quality } \\
\quad(58.3 \%)\end{array}$ & & \\
\hline "Joint" Behaviors & $r$ & & \\
\hline Reciprocity & 0.94 & & \\
\hline General atmosphere & 0.93 & & \\
\hline
\end{tabular}

Table 4. Correlations between POSER factors: Maternal, infant and "joint" behaviors

\begin{tabular}{|c|c|c|c|c|}
\hline & \multicolumn{3}{|c|}{ Infant Behaviors } & \multirow{3}{*}{$\frac{\text { "Joint" Behavior }}{\text { Quality of Interaction }}$} \\
\hline & \multirow[b]{2}{*}{ Expressivity } & \multirow{2}{*}{$\begin{array}{c}\text { Task } \\
\text { Involvement }\end{array}$} & \multirow{2}{*}{$\begin{array}{l}\text { Level of } \\
\text { Energy }\end{array}$} & \\
\hline & & & & \\
\hline \multicolumn{5}{|l|}{ Maternal behaviors } \\
\hline Sensitive involvement & $0.38 *$ & $0.42 *$ & 0.00 & $0.76^{* *}$ \\
\hline Affectionate talk & 0.16 & 0.24 & -0.06 & 0.24 \\
\hline Maternal control & -0.01 & -0.04 & -0.20 & 0.09 \\
\hline \multicolumn{5}{|l|}{ "Joint" behavior } \\
\hline Quality of interaction & $0.51 *$ & $0.59 * *$ & 0.18 & \\
\hline
\end{tabular}

$* p<0.01 . * * p<0.001$. 
Table 5. Mean scores on the POSER factors for each of the case groups and their paired controls

\begin{tabular}{|c|c|c|c|c|c|c|c|c|c|c|c|c|}
\hline & \multicolumn{2}{|c|}{$\begin{array}{l}\text { In-Patient } \\
\text { Group } \\
(n=19)\end{array}$} & \multicolumn{2}{|c|}{$\begin{array}{l}\text { Control } \\
\text { Group } \\
(n=19)\end{array}$} & \multirow[b]{2}{*}{$t$} & \multirow[b]{2}{*}{$p$} & \multicolumn{2}{|c|}{$\begin{array}{c}\text { Community } \\
\text { Depressed } \\
\text { Group } \\
(n=16)\end{array}$} & \multicolumn{2}{|c|}{$\begin{array}{l}\text { Control } \\
\text { Group } \\
(n=16)\end{array}$} & \multirow[b]{2}{*}{$t$} & \multirow[b]{2}{*}{$p$} \\
\hline & $M$ & $S D$ & $M$ & $S D$ & & & $M$ & $S D$ & $M$ & $S D$ & & \\
\hline \multicolumn{13}{|l|}{ Maternal behaviors } \\
\hline Sensitive involvement & 17.2 & 3.05 & 18.9 & 2.21 & -2.35 & $*$ & 18.4 & 1.91 & 20.1 & 1.55 & -2.6 & $*$ \\
\hline Affectionate talk & 8.8 & 2.61 & 9.2 & 2.31 & -0.57 & & 9.8 & 1.50 & 9.6 & 1.65 & -0.55 & \\
\hline Maternal control & 14.2 & 1.89 & 14.4 & 1.92 & -0.48 & & 14.5 & 1.76 & 15.4 & 1.25 & -1.94 & \\
\hline \multicolumn{13}{|l|}{ Infant behaviors } \\
\hline Expressivity & 15.9 & 2.15 & 18.1 & 4.26 & -1.93 & - & 18.1 & 4.08 & 16.8 & 3.59 & -1.23 & \\
\hline Task involvement & 11.4 & 2.33 & 11.6 & 2.23 & -0.39 & & 10.6 & 1.42 & 10.8 & 1.35 & -0.38 & \\
\hline Level of energy & 9.5 & 1.58 & 9.6 & 1.54 & -0.24 & & 9.8 & 1.36 & 9.7 & 1.71 & -0.36 & \\
\hline
\end{tabular}

Note: $(-)$ Trend, $p<0.07$.

$* p<0.05$.

be dropped from all further analyses. Sensitive involvement, was also significantly associated with Infant expressivity and Task involvement, but there was little correlation between the other dimensions of maternal and infant behavior.

Impact of postpartum maternal mental illness on the infant-mother relationship at 12 months. Matched-pair two-tailed $t$ tests showed that the IP group mothers were rated lower on Sensitive involvement than were their controls (i.e., the case group mothers were less sensitive, less appropriate in their play or expectations about the infant's ability to suceed at a task, and were more likely to express negative affect such as irritability, criticism, or sadness; $t=2.35, d f=18, p<$ 0.05; Table 5). There were no significant differences on the two remaining maternal factors. There was a trend for the case group infants to be less expressive (i.e., making fewer, more developmentally immature and negative utterances than their matched controls; $t=$ 1.93, $d f=18, p<0.07)$. Despite the positive correlation between infant Task involvement and maternal Sensitive involvement, the lack of any difference on the former variable is notable and suggests that the differences observed reflected differences in the mother's behavior in the interactions rather than the infant's contribution.
The comparisons of the CD mothers and their infants with their matched-pair controls revealed that this case group was also rated as scoring significantly lower on the component Sensitive involvement $(t=2.6, d f=15, p<$ $0.05)$. No differences were observed in the infants' behavior in the play interaction according to whether they had been exposed to maternal mental illness in the months after birth.

Eleven $(58 \%)$ of the infants in the IP group were classified as securely attached, 5 (26\%) were classified as avoidant, and $3(16 \%)$ as disorganized (see Figure 1). Similar distributions were revealed within the matched control group: $12(63 \%)$ infants were judged to be securely attached, $2(11 \%)$ were avoidant, $2(11 \%)$ were classified as avoidant/resistant (A/C), and $3(16 \%)$ as disorganized. Somewhat more striking were the results for the CD group: among the 16 infants within this group, only $6(38 \%)$ were classified as secure, $3(19 \%)$ as avoidant, and $7(44 \%)$ as disorganized. Among their respective controls, 9 $(56 \%)$ were secure, $2(13 \%)$ were avoidant, 1 (6\%) was resistant, and 4 (25\%) were disorganized.

As the numbers within these cells are small, the ratings were combined into categories of security/insecurity. Chi-square analyses revealed that there was no statistically significant association between postnatal mental illness and the status of the infant-mother at- 

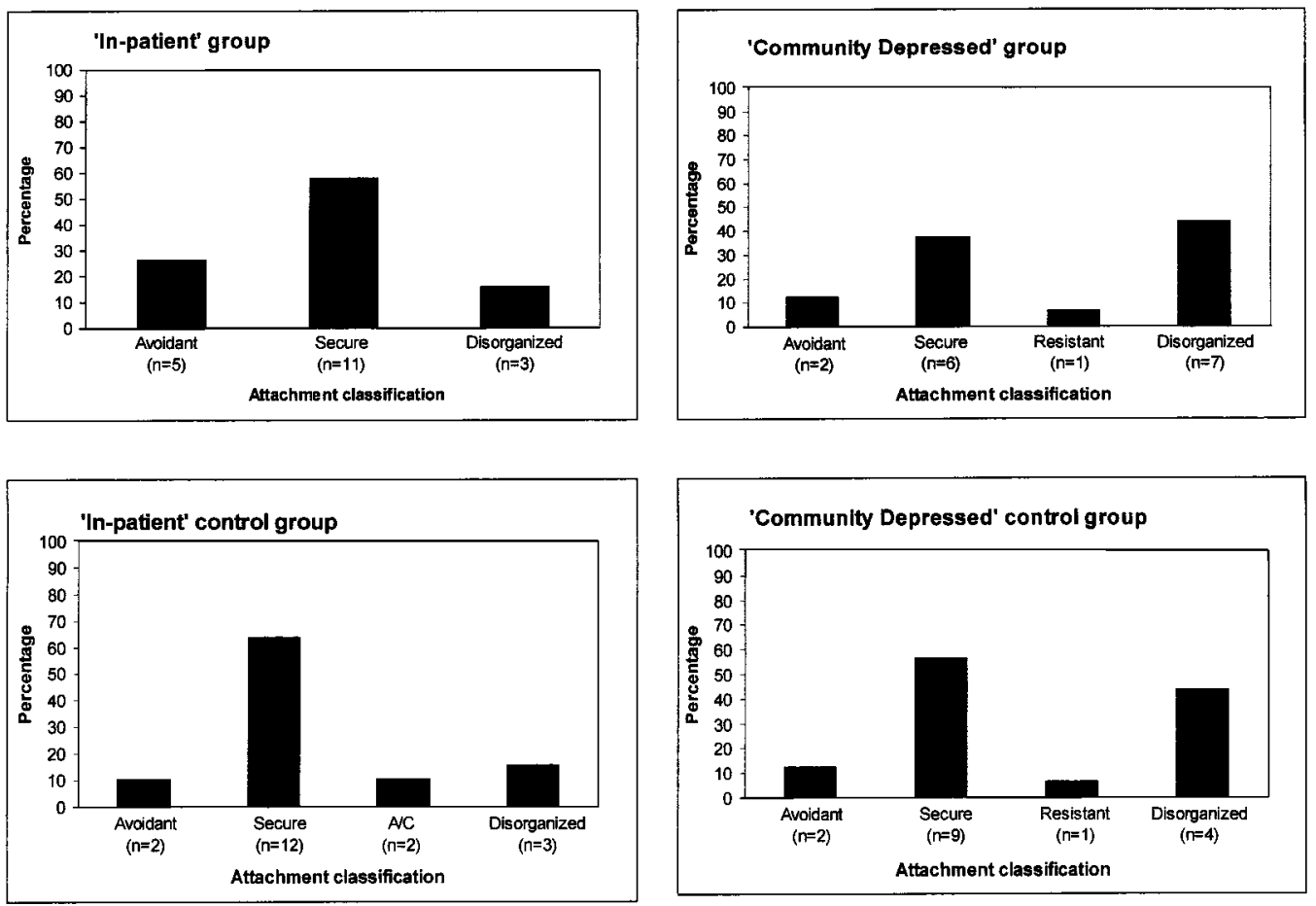

Figure 1. The infant-mother attachment classifications for the case and control groups.

tachment relationship among either the IP or the $\mathrm{CD}$ groups compared with their respective controls.

Impact on the infant at 12 months of the affective nature of severe mental disorder occurring in the puerperium. Mann-Whitney analyses were carried out on the POSER components in order to examine the impact of maternal bipolar versus unipolar disorder on the quality of mother-infant interaction. Of the six components examined, two were found to discriminate between the IP groups. Women who had been admitted to hospital for a manic/bipolar illness in the postnatal period were more likely than the women with unipolar depression to vocalize to their infant and express praise, encouragement, and affection during play (Affectionate talk: Mann-Whitney $z=1.93, p<0.05$; Table 6). However, neither of these IP groups differed from their matched-pair controls on this factor (although the difference between the IP unipolar group and their controls approached significance; Wilcoxon $z=1.77, p<0.07$ ), suggesting that the differences observed were part of the normal variance of behaviors in the study sample.

A similar difference between the two IP groups emerged on the infant behavior factor Task involvement. The Mann-Whitney analysis showed that the infants of the mothers who had experienced a manic or bipolar illness were more likely to persist in a task or attend to a toy or to their mother's suggestions than were the infants of unipolar depressed mothers $(z=2.0, p<0.05)$. Again, the differences between the IP groups did not obtain in comparisons with their respective controls on Wilcoxon matched-pair tests.

The infant-mother attachment classifications of security/insecurity fell unexpectedly into two groups when the nature of the IP mothers' illness was considered (see Figure 2). Only 1 of the 10 infants of manic/bipolar disordered mothers displayed insecure patterns of behavior with his or her mother in the Strange Situation. This child's attachment strategy was disorganized. In contrast, 7 of the 9 infants of mothers who had had a psy- 
Table 6. Mean POSER scores for the in-patient groups and the unipolar depressed groups

\begin{tabular}{|c|c|c|c|c|c|c|c|c|c|c|c|c|}
\hline & \multicolumn{4}{|c|}{ In-Patient Groups } & \multirow[b]{4}{*}{$z$} & \multirow[b]{4}{*}{$p$} & \multirow{2}{*}{\multicolumn{4}{|c|}{ Unipolar Depression Groups }} & \multirow[b]{4}{*}{$z$} & \multirow[b]{4}{*}{$p$} \\
\hline & \multirow{2}{*}{\multicolumn{2}{|c|}{$\begin{array}{l}\text { Unipolar } \\
\text { Depression } \\
(n=9)\end{array}$}} & \multirow{2}{*}{\multicolumn{2}{|c|}{$\begin{array}{l}\text { Biopolar/ } \\
\text { Manic } \\
\text { Disorder } \\
(n=10)\end{array}$}} & & & & & & & & \\
\hline & & & & & & & \multicolumn{2}{|c|}{$\begin{array}{l}\text { In-patient } \\
\text { Group } \\
(n=9)\end{array}$} & \multicolumn{2}{|c|}{$\begin{array}{c}\text { Community } \\
\text { Group } \\
(n=16)\end{array}$} & & \\
\hline & $M$ & $S D$ & $M$ & $S D$ & & & $M$ & $S D$ & $M$ & $S D$ & & \\
\hline \multicolumn{13}{|l|}{ Maternal behaviors } \\
\hline Sensitive involvement & 16.6 & 3.23 & 17.7 & 2.97 & 1.06 & & 16.6 & 3.23 & 18.5 & 1.95 & 1.56 & \\
\hline Affectionate talk & 7.9 & 2.18 & 9.6 & 1.79 & 1.93 & $*$ & 7.9 & 2.18 & 9.5 & 1.70 & 2.16 & $*$ \\
\hline Maternal control & 13.6 & 1.94 & 14.7 & 1.79 & 1.35 & & 13.6 & 1.94 & 14.5 & 1.76 & 0.96 & \\
\hline \multicolumn{13}{|l|}{ Infant behaviors } \\
\hline Expressivity & 15.5 & 1.92 & 16.3 & 2.37 & 1.02 & & 15.5 & 1.92 & 18.1 & 4.08 & 1.62 & \\
\hline Task involvement & 10.3 & 2.06 & 12.4 & 2.19 & 2.0 & $*$ & 10.3 & 2.06 & 10.6 & 1.42 & 0.54 & \\
\hline Level of energy & 10.1 & 0.96 & 9.0 & 1.89 & 0.95 & & 10.1 & 0.96 & 9.8 & 1.36 & 0.39 & \\
\hline
\end{tabular}

$* p<0.05$.

chotic/nonpsychotic depression were rated as insecurely attached. Five of these infants were judged to be avoidant and 2 were classified as disorganized. There was no pattern that related to whether the mother's depression had had psychotic features or not. Fisher's exact test confirmed that there was a significant association between attachment security and the nature of the IP mothers' illness (two-tailed $p<0.01)$.

Impact of severe maternal depression requiring hospitalization compared with less severe depression without hospitalization. MannWhitney analyses revealed a difference between the IP depressed and CD groups of mothers on the POSER factor of Affectionate talk (see Table 6). There seemed to be an effect of prior severity of depression as the IP group mothers were less likely to vocalize to the infant and the content of their speech was less positive than the CD group women.

In both the IP unipolar depressed group and the CD groups, there was a high proportion of infants classified as insecurely attached to their mother. Among the IP group this rate was $78 \%$ (seven out of nine infants), and among the CD group $62 \%$ met criteria for insecurity. Chi-square analysis revealed no difference between the groups.

Given the unexpected association between attachment security and the affective nature of the IP mothers' illness in the postpartum period, a limited number of post hoc analyses were carried out to examine whether this effect was a function of other qualities of the mothers' illness, such as chronicity, timing, or severity. Because of the similarity in the rates of infant attachment security between the IP unipolar and CD groups, subsequent analyses included the $\mathrm{CD}$ group of mothers and their infants $(n=35)$.

Chi-square analyses showed that the timing of onset of the mothers' illness (median split) and whether or not the mother was taking prescribed medication at 12 months were unrelated to attachment security. Similarly, there were no differences in attachment status according to the reported length of the mothers' illness or the timing of the "worst week." However, the number of clinically significant symptoms experienced during the "worst week" (Mann-Whitney $z=2.07, p<0.05$ ) and whether or not the mother reported any concurrent symptoms at 12 months $\left(\chi^{2}=4.1\right.$, $d f=1, p<0.05)$ were both found to be associated with attachment security. The mothers of insecure infants reported fewer psychiatric symptoms during the peak of their illness (insecure: $8.1, S D=1.95$; secure: $10.4, S D=$ 3.41 ), whereas, at 12 months, $50 \%$ of insecurely attached infants had mothers who reported some residual psychiatric symptoms on the SADS (compared with $18 \%$ of secure in- 

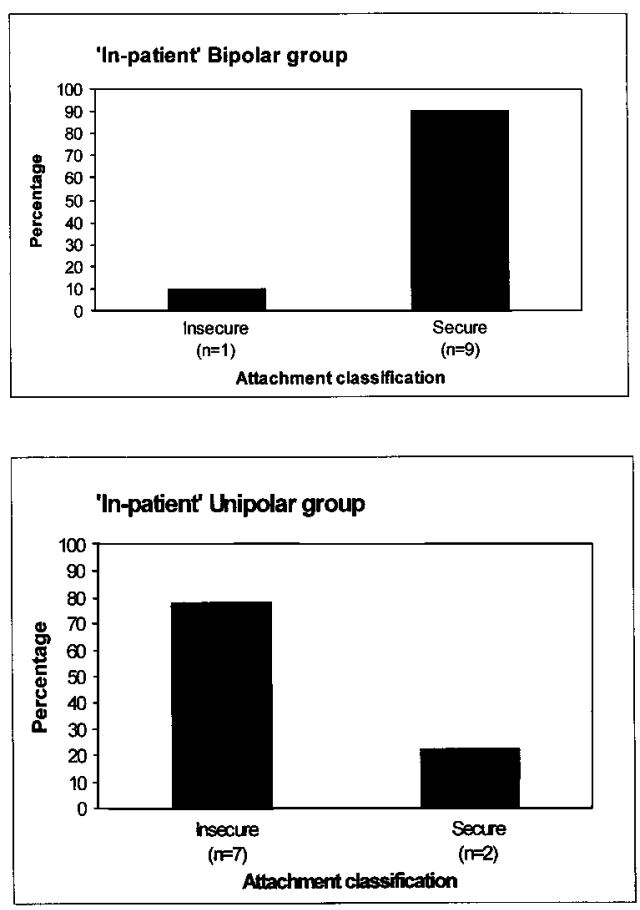

Figure 2. The infant-mother attachment classifications for the in-patient bipolar and unipolar groups.

fants). The difference in the number of symptoms during the worst week was not due to mothers with bipolar disorder reporting a mixed manic/depressive state.

A logistic regression analysis was then conducted to examine which of these variables (i.e., affective nature of the mothers' illness, presence of psychiatric symptomatology at 12 months, and number of symptoms during the "worst week" of the illness) was most strongly predictive of attachment security. The analysis revealed that the best fit model for attachment security comprised the affective nature of the mothers' illness in the postpartum period only (Model $\chi^{2}=10.7, d f=1$, $p=0.001)$.

A second logistic regression analysis was conducted which included the two POSER factors that discriminated between the IP unipolar/bipolar disordered groups (i.e., Affectionate talk and infant Task involvement). Although Task involvement made a significant contribution to a model of security (Model $\chi^{2}$ $=6.1, d f=1, p<0.02)$ whereby infants who were classified as securely attached were more likely to engage in and persist at the tasks set during the play observation, the predictive value of this variable became negligible when the affective nature of the mother's illness was also included.

\section{Discussion}

The results of the current study suggested that severe postnatal mental illness continued to have some impact on the mother's ability to interact with her child at 12 months in a way that impaired mutually satisfying, reciprocal play. Thus, compared with their matched controls, the case group mothers were observed to be less sensitive, less appropriate, and more negative in their play. Because of the close pairwise matching of cases with controls on demographic characteristics, the findings cannot be easily explained by social disadvantage such as low occupational status, or single parenthood. Two other findings lend support to the notion that the difference was a function of the postnatal episode of maternal illness. Firstly, it was revealed despite maternal reports of a return to premorbid state, a finding which has also been reported in a number of other studies (e.g., Murray, 1992; Stein et al., 1991; Weissman, Paykel, \& Klerman, 1972). Secondly, differences in interaction were somewhat more apparent in the context of severe illness requiring admission of the mother to hospital than less severe illness where mothers remained in the community.

When the IP sample was considered as a whole, there was no evidence that an episode of postnatal illness was associated with subsequent insecure attachment. This finding gains support from other investigations of severe postpartum illness (McNeil et al., 1988; Näslund et al., 1984; Persson-Blennow et al., 1988; Sameroff et al., 1982). It seemed that although observable differences in the mothers' behavior remained at 12 months, these were not sufficiently deviant to have an adverse impact on the child's behavior (see also Murray et al., 1996) or on the mother-child relationship at this stage. However, the findings also strongly highlighted the importance of sample homogeneity (in terms of the affective 
nature of the mother's illness) in order that specific effects on the child can be detected.

The finding that $68 \%$ of the infants of mothers who had an episode of unipolar depression (IP and CD groups combined) displayed behaviors indicative of an insecure attachment relationship was striking, but does find some support in the literature (e.g., Cicchetti et al., 1998; Murray, 1992). Furthermore, the high rate $(36 \%)$ of disorganized infant behavior within this group was of particular concern given that this attachment typology is known to constitute a significant risk factor for subsequent social, emotional, and cognitive problems (e.g., Lyons-Ruth et al., 1997; Main \& Solomon, 1990; Teti, Gelfand, Messinger, \& Isabella, 1995). Somewhat more striking, however, was the close association between maternal postnatal illness of a manic nature and the likelihood of attachment security.

Although the unipolar/bipolar difference in infant attachment classification gained support from independent observations of mother-infant interaction in the present study (Ainsworth et al., 1978), the finding stands in contrast to the results reported by Radke-Yarrow et al. (1985) in which children of bipolar mothers were more likely to be insecurely attached than children of unipolar depressed mothers. However, both studies have been limited by small numbers of mothers with bipolar disorder, and, in addition, there are substantial differences between the samples that may help to explain the discrepant findings. In the study of Radke-Yarrow and colleagues, parents with a history of psychiatric illness were to some extent self-selected by recruitment to the study via advertising in the community. The 14 children of bipolar-disordered mothers ranged in age from 30 to 47 months, and the mean percentage of the child's lifetime that the mother had been ill was $40 \%$ (range, $0-100 \%$ ), the majority of whom had not been hospitalized since the child's birth. Due to the older age of the children, the study modified the Strange Situation procedure and scoring reportedly placed more stress on avoidance and resistance behaviors. Furthermore, the development of the D classification system subsequent to Radke-Yarrow et al.'s study may have had implications for the rates of insecurity reported. For example, in the current study, coding for the disorganized/disoriented attachment behaviors identified 6 children of unipolar depressed mothers who had previously been classified as secure (as assessed by the A, B, C system), such that the rate of insecurity increased from 44 (11/ $25)$ to $68 \%(17 / 25)$. In comparison, coding for $\mathrm{D}$ made little difference to the attachment classification of children of bipolar disordered mothers.

Regardless of the sampling and methodological differences between the studies, developmental change may also account for the disparate results. A number of investigators have suggested that the association between parental and child maladjustment increases with the child's increasing age (Cohn et al., 1990; Zahn-Waxler, Kochanska, Krupnick, \& McKnew, 1990). For example, there is evidence of a deterioration in the infant-mother attachment relationship between 12 and 18 months within clinical groups or where the mother is otherwise "psychologically unavailable" (e.g., Egeland \& Sroufe, 1981; Gaensbauer et al., 1984; Radke-Yarrow, 1987; Schneider-Rosen, Braunwald, Carlson, \& Cicchetti, 1985). Egeland and Sroufe (1981) found that $43 \%$ of the 12-month-old infants with "psychologically unavailable" mothers were classified as avoidant in the Strange Situation, whereas at 18 months all of the infants were insecurely attached. Stern (1985) and Radke-Yarrow (1987) describe important changes in the quality of infant-mother communication towards the end of the 1 st year whereby infants become more autonomous in regulating their own behavior, begin to monitor adult expressions of affect more closely, and seek more active emotional contact with the mother when she becomes angry or distressed. An increase in active emotional contact with a mother who may be susceptible to psychopathology may also have a progressively deleterious effect on the quality of the mother-child relationship even if it is not apparent in the early childhood years. It is possible that undesirable sequelae may emerge much later for the infants of the mothers with a manic/bipolar disorder in the current sample 
(see Radke-Yarrow, Nottelmann, Martinez, Fox, \& Belmont, 1992). In order to be useful, therefore, comparisons between studies must take account of the developmental stage at which the child is exposed to maternal mental illness as well as the age at which outcome is evaluated (Hipwell \& Kumar, 1997).

The reason for the development of the different attachment strategies among the infants of mothers with unipolar and bipolar disorder is not clear from the current study. They do not appear to have arisen as a function of the duration or timing of the mother's illness, or the extent to which the psychiatric episode had remitted by 12 months. Several alternative hypotheses are possible. First, it may have been that different patterns of interaction were set in train at the time of the episode in the puerperium. Data reported by Hipwell and Kumar (1996), however, showed that there was no continuity in the quality of mother-infant interaction observed during MBU admission and during observations of play at 12 months. In fact, ratings of the early interactions of the manic/bipolar disordered group revealed a more disturbed pattern than the interactions of the IP depressed mothers. Similarly, Murray et al. (1995) reported no evidence of an association between the quality of early mother-infant interactions and attachment security among women who became mentally ill in the postnatal period. These investigators, however, did find that the presence of postnatal illness and social adversity predicted the quality of the infant-mother attachment relationship at 18 months.

Second, there may have been effects arising from differences in the management of the IP women which had an impact on the degree to which the infant was either exposed to psychiatric symptoms or was separated from the mother. This is suggested by the bipolar-disordered mothers' own reports of a greater number of clinically significant symptoms during the peak of their illness compared with women who were diagnosed with unipolar disorder. MBU staff may have perceived these women to have been more disturbed during the period of admission and, as a result, may have been more involved in the care of these infants. Thus, the infants may have had less exposure to maternal psychopathology, in addition to compensatory experiences with substitute caregivers which buffered them from adverse effects. The index of separation used in the current study was too crude to provide an accurate picture of the degree or type of infant exposure to maternal illness, but clinical impressions suggested that fewer efforts were made to minimize the contact that mothers with unipolar depression had with their infants. It is possible, then, that there was greater risk for these infants of exposure to chronically low-level affective symptoms and maladaptive parenting (i.e., chronicity as a function of management). Previous reports of the relative impact on the child of chronicity of the parents' illness rather than diagnosis per se (e.g., Cytryn et al., 1984; Sameroff et al., 1982; Sneddon, Kerry, \& Bant, 1981) have not generally considered issues of treatment and management. Data available in the current study did not show any differences in management or support following discharge from the MBU according to the affective nature of the mothers' illness.

Third, there may have been trait differences between the mothers that influenced their behavior when they were free from psychiatric symptomatology. Support for this notion comes from a study of individuals who had previously suffered episodes of bipolar or unipolar illness but who were well at the time of assessment (Perris, 1966). A number of personality differences were reported: bipolardisordered patients tended to be warm, energetic, and extraverted, whereas unipolar-disordered patients were more often retiring, tense, and anxious. Weissman et al. (1972) also described enduring impairment in emotional relationships and child rearing despite remission of manifest symptoms of depression that were attributed to some characteristic of the mothers' personality. It may have been these differences that were detected using the POSER. Alternatively, it may have been that the mothers were experiencing subclinical symptoms of mania or depression at 12 months that were not revealed during the psychiatric interviews.

Other factors that may have played a role 
in the current findings include the nature of the mothers' own experience of parenting (van Ijzendoorn et al., 1995) and the contribution made by the infants' father. Harvey and McGrath (1988) and Lovestone and Kumar (1993), for example, have reported high rates of depression among the partners of women admitted to an MBU. Although little is known about the impact of such additional risk factors on the child, there is some evidence (e.g., Radke-Yarrow et al., 1985) to suggest that the influence of the fathers' illness on infantmother attachment is minimal.

The validity of translating measures that have been standardized within healthy populations to a severely mentally ill sample must be considered. For example, much of the predictive power of early measures of infant functioning depends on an element of stability and continuity in the family and social environment. Families in which a parent is mentally ill, however, are likely to be characterized by instability and discontinuity of care. More specifically, the Strange Situation procedure relies on the premise that the child experiences sufficient stress from the situation and the separation from the caregiver that the child's attachment system becomes activated. It is possible that infants who have had experience of multiple caregiving in the MBU and repeated, though temporary, separations from the mother may have become tolerant to unpredictable variations in the interpersonal en-

\section{References}

Ainsworth, M. D. S., Blehar, M. C., Waters, E., \& Wall, S. (1978). Patterns of attachment. Hillsdale, NJ: Erlbaum.

Appleby, L., \& Dickens, C. (1993). Mothering skills of women with mental illness. British Medical Journal, 306, 348-349.

Bartko, J. J. (1966). The intraclass correlation coefficient as a measure of reliability. Psychological Reports, 19, 3-11.

Bartko, J. J. (1976). On various intraclass correlation reliability coefficients. Psychological Bulletin, 83, 762765.

Bates, J. E., Maslin, C. A., \& Frankel, K. A. (1985). Attachment security, mother-child interaction, and temperament as predictors of behaviour problem ratings at three years. Monographs of the Society for Research in Child Development, 50(1/2, Serial No. 209), 167-193.

Bowlby, J. (1982). Attachment and loss: Vol. 1. Attachment (2nd ed.). New York: Basic. vironment and thus less likely to display behaviors on reunion that can be classified as insecure. The attachment behaviors of the IP infants of mothers with unipolar disorder, however, do not lend support to this notion.

It is also possible that the sequence of the procedures in the current study may have influenced the display of infant attachment behaviors. By conducting the play observation prior to the Strange Situation, it may have been that the infants became sufficiently accustomed to the environment and the involvement of unfamiliar adults that attachment behaviors were differentially reduced across the groups. However, the ratings of proximity seeking and contact maintenance among the case group infants were found to be no different from those of their matched controls, which suggests that there was little difference between the groups in terms of the "strangeness" of the procedure. Nevertheless, detailed analysis of the infants' behavior during the separation episodes would address this question more adequately.

Long-term follow-up is necessary to examine the persistence and clinical implications of the effects reported here and whether these early indications of resilience or risk of disturbance among the infants of mothers who are severely disordered in the puerperium are maintained. In addition, the small sample size of the present study clearly demands a need for replication of the findings.

Bretherton, I. (1985). Attachment theory: Retrospect and prospect. Monographs of the Society for Research in Child Development, 50(1/2, Serial No. 209), 3-37.

Cicchetti, D., Ganiban, J., \& Barnett, D. (1991). Contributions from the study of high risk populations to understanding the development of emotion regulation. In J. Garber \& K. A. Dodge (Eds.), The development of emotion regulation and dysregulation (pp. 15-48). Cambridge: Cambridge University Press.

Cicchetti, D., Rogosch, F. A., \& Toth, S. L. (1998). Maternal depressive disorder and contextual risk: Contributions to the development of attachment insecurity and behavior problems in toddlerhood. Development and Psychopathology, 10, 283-300.

Cicchetti, D., \& Toth, S. L. (1998). The development of depression in children and adolescents. American Psychologist, 53, 221-241.

Cicchetti, D., Toth, S. L., \& Lynch, M. (1995). Bowlby's dream comes full circle: The application of attachment theory to risk and psychopathology. In T. H. 
Ollendick \& R. J. Prinz (Eds.), Advances in clinical child psychology (Vol. 17, pp. 1-75). New York: Plenum Press.

Cogill, S. R., Caplan, H. L., Alexandra, H., Robson, K. M., \& Kumar, R. (1986). Impact of maternal postnatal depression on cognitive development of young children. British Medical Journal, 292, 1165-1167.

Cohn, J. F., Campbell, S. B., Matias, R., \& Hopkins, J. (1990). Face-to-face interactions of postpartum depressed and nondepressed mother-infant pairs at 2 months. Developmental Psychology, 26, 15-23.

Cohn, J. F., \& Tronick, E. (1989). Specificity of infants' response to mothers' affective behaviour. Journal of the American Academy of Child and Adolescent Psychiatry, 28, 242-248.

Connell, D. B. (1977). Individual differences in attachment behavior: Long-term stability and relationship to language development. Doctoral dissertation, Syracuse University. (University Microfilms No. 77-30-717)

Cox, J. L., Holden, J. M., \& Sagovsky, R. (1987). Detection of postnatal depression: Development of the Edinburgh Postnatal Depression Scale. British Journal of Psychiatry, 150, 782-786.

Cummings, E. M., \& Cicchetti, D. (1990). Attachment, depression, and the transmission of depression. In M. T. Greenberg, D. Cicchetti, \& E. M. Cummings (Eds.), Attachment in the preschool years: Theory, research and intervention (pp. 339-375). Chicago: University of Chicago Press.

Cytryn, L., McKnew, D. H., Zahn-Waxler, C., RadkeYarrow, M., Gaensbauer, T. J., Harmon, R. J., \& Lamour, M. (1984). A developmental view of affective disturbances in the children of affectively ill parents. American Journal of Psychiatry, 141, 219-222.

D'Angelo, E. J. (1986). Security of attachment in infants with schizophrenic, depressed and unaffected mothers. Journal of Genetic Psychology, 147, 421-422.

Davenport, Y. B., Zahn-Waxler, C., Adland, M. L., \& Mayfield, A. (1984). Early child-rearing practices in families with a manic-depressive parent. American Journal of Psychiatry, 141, 230-235.

DeMulder, E., \& Radke-Yarrow, M. (1991). Attachment with affectively ill and well mothers: Concurrent behavioral correlates. Development and Psychopathology, 3, 227-242.

Egeland, B., \& Sroufe, L. A. (1981). Attachment and early maltreatment. Child Development, 52, 44-52.

Endicott, J., \& Spitzer, R. L. (1978). A diagnostic interview: The Schedule for Affective Disorders and Schizophrenia. Archives of General Psychiatry, 35, 837-844.

Field, T. M. (1992). Infants of depressed mothers. Development and Psychopathology, 4, 49-66.

Field, T. M., Healy, B., Goldstein, S., \& Guthertz, M (1990). Behavior-state matching and synchrony in mother-infant interactions of nondepressed vs depressed dyads. Developmental Psychology, 26, 7-14.

Field, T. M., Healy, B., Goldstein, S., Perry, S., Schanberg, S., Zimmerman, E., \& Kuhn, C. (1988). Infants of depressed mothers show "depressed" behaviour even with non-depressed adults. Child Development, 59, 1569-1579.

Fleming, A. S., Ruble, D. N., Flett, G. L., \& Shaul, D (1988). Postpartum adjustment in first-time mothers: Relations between mood, maternal attitudes, and mother-infant interaction. Developmental Psychol ogy, 24, 71-81.

Frankel, K. A., \& Bates, J. E. (1990). Mother-toddler problem solving: Antecedents in attachment, home behavior, and temperament. Child Development, 61, 810-819.
Gaensbauer, T. J., Harmon, R. J., Cytryn, L., \& McKnew, D. H. (1984). Social and affective development in infants with a manic-depressive parent. American Journal of Psychiatry, 141, 223-229.

Goldsmith, H. H., \& Alansky, J. A. (1987). Maternal and infant temperamental predictors of attachment: A meta-analytic review. Journal of Consulting and Clinical Psychology, 55, 805-816.

Goodman, S. H., \& Brumley, H. E. (1990). Schizophrenic and depressed mothers: Relational deficits in parenting. Developmental Psychology 26, 31-39.

Grossmann, K., Grossmann, K. E., Spangler, G., Suess, G., \& Unzer, L. (1985). Maternal sensitivity and newborn's orientation responses as related to quality of attachment in Northern Germany. Monographs of the Society for Research in Child Development, 50(1/2, Serial No. 209), 233-256.

Harvey, I., \& McGrath, G. (1988). Psychiatric morbidity in spouses of women admitted to a mother and baby unit. British Journal of Psychiatry, 152, 506-510.

Hay, D., \& Kumar, R. (1995). Interpreting the effects of postnatal depression on children's intellectual development: A critique and reanalysis. Child Psychiatry and Human Development, 253, 165-181.

Hipwell, A. E., \& Kumar, R. (1996). Maternal psychopathology and prediction of outcome based on Mother-Infant Interaction Ratings (BMIS). British Journal of Psychiatry, 169, 655-661.

Hipwell, A. E., \& Kumar, R. (1997). The impact of postpartum affective psychosis on the child. In L. Murray \& P. J. Cooper (Eds.), Postpartum depression and child development (pp. 265-293). New York: Guilford Press.

Kumar, R. (1992). Mentally ill mothers and their babies: What are the benefits and risks of joint hospital admission? In K. Hawton \& P. Cowen (Eds.), Practical problems in clinical psychiatry (pp. 184-197). Oxford: Oxford University Press.

Kumar, R., \& Hipwell, A. E. (1994). Implications for the infant of maternal puerperal psychiatric disorders. In M. Rutter, E. Taylor, \& L. Hersov (Eds.), Child and adolescent psychiatry: Modern approaches (pp. 759775). Oxford: Blackwell.

Kumar, R., \& Hipwell, A. E. (1996). Development of a clinical rating scale to assess mother-infant interaction in a psychiatric mother and baby unit. British Journal of Psychiatry, 169, 18-26.

Kumar, R., Marks, M., Platz, C., \& Yoshida, K. (1995). Clinical survey of a psychiatric mother and baby unit: Characteristics of 100 consecutive admissions. Journal of Affective Disorders, 33, 11-22.

Lovestone, S., \& Kumar, R. (1993). Postnatal psychiatric illness: The impact on partners. British Journal of Psychiatry, 163, 210-216.

Lyons-Ruth, K., Easterbrooks, M., \& Cibelli, C. (1997). Infant attachment strategies, infant mental lag, and maternal depressive symptoms: Predictors of internalising and externalising problems at age 7. Developmental Psychology, 33, 681-692.

Lyons-Ruth, K., Zoll, D., Connell, D., \& Grunebaum, H. U. (1986). The depressed mother and her one-yearold infant: Environment, interaction, attachment, and infant development. In E. Z. Tronick \& T. Field (Eds.), Maternal depression and infant disturbance: New directions for child development (Vol. 34, pp. 61-82). San Francisco: Jossey-Bass.

Main, M. (1983). Exploration, play, and cognitive functioning related to infant-mother attachment. Infant Behaviour and Development, 6, 167-174. 
Main, M., Kaplan, N., \& Cassidy, J. (1985). Security in infancy, childhood and adulthood: A move to the level of representation. Monographs of the Society for Research in Child Development, 50(1/2, Serial No. 209), 66-104.

Main, M., \& Solomon, J. (1990). Procedures for identifying infants as disorganized-disoriented during the Ainsworth Strange Situation. In M. Greenberg, D. Cicchetti, \& E. Cummings (Eds.), Attachment in the preschool years: Theory, research and intervention (pp. 121-160). Chicago: University of Chicago Press.

Main, M., \& Weston, D. (1982). Avoidance of the attachment figure in infancy: Descriptions and interpretations. In C. M. Parke \& J. Stevenson-Hinde (Eds.), The place of attachment in human behavior (pp. 203217). New York: Basic Books.

Margison, F. R. (1982). The pathology of the motherchild relationship. In I. F. Brockington \& R. Kumar (Eds.), Motherhood and mental illness (pp. 191-222). London: Academic Press.

Margison, F. R. (1990). Infants of mentally ill mothers: The risk of injury and its control. Journal of Reproductive and Infant Psychology, 8, 137-146.

McNeil, T. F., Näslund, B., Persson-Blennow, I., \& Kaij, L. (1985). Offspring of women with nonorganic psychosis: Mother-infant interaction at three-and-a-half and six months of age. Acta Psychiatrica Scandinavica, 71, 551-558.

McNeil, T. F., Persson-Blennow, I., Binett, B., Harty, B., \& Karyd, U.-B. (1988). A prospective study of postpartum psychoses in a high-risk group. 7. Relationship to later offspring characteristics. Acta Psychiatrica Scandinavica, 78, 613-617.

Melhuish, E. C., Gambles, C., \& Kumar, R. (1988). Maternal mental illness and the mother-infant relationship. In R. Kumar \& I. F. Brockington (Eds.), Motherhood and mental illness: Vol. 2. Causes and consequences (pp. 191-211). London: Wright/Butterworth.

Murray, L. (1988). Effects of postnatal depression on infant development: Direct studies of early mother-infant interactions. In R. Kumar \& I. F. Brockington (Eds.), Motherhood and mental illness: Vol. 2. Causes and consequences (pp. 159-190). London: Wright/ Butterworth.

Murray, L. (1992). The impact of postnatal depression on infant development. Journal of Child Psychology and Psychiatry, 33, 543-561.

Murray, L., Fiori-Cowley, A., Hooper, R., \& Cooper, P. J. (1996). The impact of postnatal depression and associated adversity on early mother infant interactions and later infant outcome. Child Development, 67, 2512-2526.

Murray, L., Kempton, C., Woolgar, M., \& Hooper, R. (1993). Depressed mothers' speech to their infants and its relation to infant gender and cognitive development. Journal of Child Psychology and Psychiatry, 34, 1083-1101.

Näslund, B., Persson-Blennow, I., McNeil, T., Kaij, L., \& Malmquist-Larsson, A. (1984). Offspring of women with nonorganic psychosis: Infant attachment to the mother at one year of age. Acta Psychiatrica Scandinavica, 69, 231-241.

Perris, C. (1966). A study of bipolar (manic-depressive) and unipolar recurrent depressive psychoses. Acta Psychiatrica Scandinavica, 42(Suppl. 194), 7-189.

Persson-Blennow, I., Binett, B., \& McNeil, T. F. (1988). Offspring of women with nonorganic psychosis: An- tecedents of anxious attachment to the mother at one year of age. Acta Psychiatrica Scandinavica, 78, $66-71$.

Persson-Blennow, I., Näslund, B., McNeil, T. F., \& Kaij, L. (1986). Offspring of women with nonorganic psychosis: Mother-infant interaction at one year of age. Acta Psychiatrica Scandinavica, 73, 207-213.

Pound, A., Cox, A. D., Puckering, C., \& Mills, M (1985). The impact of maternal depression on young children. Book Supplement to the Journal of Child Psychology and Psychiatry, 2(4), pp. 3-10.

Radke-Yarrow, M. (1987, June). Attachment in the context of psychopathology. Presentation at a conference on "Fruits of Attachment Theory: Findings and Applications Across the Life Cycle," London.

Radke-Yarrow, M., Cummings, E. M., Kuczynski, L., \& Chapman, M. (1985). Patterns of attachment in twoand three-year-olds in normal families and families with parental depression. Child Development 56, 884-893.

Radke-Yarrow, M., McCann, K., DeMulder, E., Belmont, B., Martinez, P., \& Richardson, D. (1995). Attachment in the context of high-risk conditions. Development and Psychopathology, 7, 247-263.

Radke-Yarrow, M., Nottelmann, E., Martinez, P., Fox, M. B., \& Belmont, B. (1992). Young children of affectively ill parents: A longitudinal study of psychosocial development. Journal of the American Academy of Child and Adolescent Psychiatry, 31, 68-77.

Registrar General (1980). Classification of occupations. London: HMSO.

Renken, B., Egeland, B., Marvinney, D., Mangelsdorf, S., \& Sroufe, L. A. (1989). Early childhood antecedents of aggression and passive-withdrawal in early elementary school. Journal of Personality, 57, 257281

Sameroff, A. J., Seifer, R., \& Zax, M. (1982). Early development of children at risk for emotional disorder. Monographs of the Society for Research in Child Development, 47, 1-82.

Schneider-Rosen, K., Braunwald, K. G., Carlson, V., \& Cicchetti, D. (1985). Current perspectives in attachment theory: Illustration from the study of maltreated infants. In I. Bretherton \& E. Waters (Eds.), Growing points of attachment: Theory and research. Monographs of the Society for Research in Child Development, 50(1/2, Serial No. 209), 194-210.

Sharp, D., Hay, D., Pawlby, S., Schmücker, G., \& Kumar, R. (1995). Impact of maternal depression during infancy on the subsequent psychological development of boys and girls. Journal of Child Psychology and Psychiatry, 36, 1315-1336.

Sneddon, J., Kerry, R. J., \& Bant, W. P. (1981). The psychiatric mother and baby unit. The Practitioner, 225, 1295-1300

Spitzer, R. L., Endicott, J., \& Robins, E. (1978). Research Diagnostic Criteria: Rationale and reliability. Archives of General Psychiatry, 36, 773-782.

Stein, A., Gath, D. H., Bucher, J., Bond, A., Day, A., \& Cooper, P. J. (1991). The relationship between postnatal depression and mother-child interaction. British Journal of Psychiatry, 158, 46-52.

Stern, D. N. (1985). The interpersonal world of the infant. A view from psychoanalysis and developmental psychology. New York: Basic.

Teti, D., Gelfand, D., Messinger, D., \& Isabella, R. (1995). Maternal depression and the quality of early attachment: An examination of infants, preschoolers, 
and their mothers. Developmental Psychology, 31, 364-376.

Teti, D., \& Nakagawa, M. (1990). Assessing attachment in infants: The Strange Situation and alternate systems. In E. Gibbs \& D. Teti (Eds.), Interdisciplinary assessment of infants: A guide for intervention professionals (pp. 191-214). Baltimore: Paul H. Brookes.

Theils, C., \& Kumar, R. (1987). Severe puerperal mental illness and disturbances of maternal behavior. Journal of Psychosomatic Obstetrics and Gynaecology, 7, 27-38.

van Ijzendoorn, M. H., Goldberg, S., Kroonenberg, P. M., \& Frenkel, O. J. (1992). The relative effects of maternal and child problems on the quality of attachment: A meta-analysis of attachment in clinical samples. Child Development, 63, 840-858.

van Ijzendoorn, M. H., Juffer, J., \& Duyvesteyn, M. G. C. (1995). Breaking the intergenerational cycle of insecure attachment: A review of the effects of attachment-based interventions on maternal sensitivity and infant security. Journal of Child Psychology and Psychiatry, 36, 225-248.

van Ijzendoorn, M. H., van der Verr, R., \& van VlietVisser, S. (1987). Mother-infant attachment and developmental status in kindergarten. In L. W. C. Tavecchio \& M. H. van Ijzendoorn (Eds.), Attachment in social networks (pp. 185-225). Amsterdam: Elsevier.

Waters, E. (1978). The reliability and stability of individual differences in infant-mother attachment. Child Development, 39, 483-494.

Weissman, M. M., Paykel, E., \& Klerman, G. L. (1972). The depressed woman as a mother. Social Psychiatry, 7, 98-108.

Wolke, D. (1986). Play Observation Scheme and Emotion Rating (POSER). Unpublished manual, Institute of Child Health, London.

Zahn-Waxler, C., Kochanska, G., Krupnick, J., \& McKnew, D. (1990). Patterns of guilt in children of depressed and well mothers. Developmental Psychology, 26, 51-59. 